glaciated region would cause a constant succession of cyclones accompanied by a high rainfall over the Mediterranean and Western Asia. This would support the view that the desert belt of the Sahara was then more to the south, thus accounting for the vast number of palæolithic implements, accompanied by ostrich shells, found in that area. It would also strengthen the probability that man drifted north as the climate improved after the Würm period, and confirm the suggestion of the archæological evidence that after the Aurignacian period there is no break.

A series of recent investigations on the south coast in Hampshire and Sussex, which were described by Dr. L. S. Palmer, bear very directly upon the question of the equation with Continental deposits. Dr. Palmer, who worked in collaboration with a geologist, had endeavoured to relate climate and deposits with implements. As a result, the Ioo $\mathrm{ft}$. terraces and beaches show a warm fauna associated with Acheulean and early Mousterian implements ; the $50 \mathrm{ft}$. and $\mathrm{I}_{5} \mathrm{ft}$. terraces a cold fauna associated with Mousterian implements, the cold period being interrupted by a slightly warmer period which justified the division of this phase into two parts. In the superficial brick earths were the Aurignacian, and over the latest Combe rock were the Magdalenian implements. Dr. Palmer found a correspondence between climate, culture, and land oscillations. The investigations were carried out without reference to nomenclature, but on comparison, corresponded with the Continental system of Penck.

At this point the discussion closed. If it had attained no very definite conclusion, the air had been cleared. One definite question has been formulated for further investigation, and it has been shown that a considerable body of opinion is approaching some kind of an agreement as to the manner in which the evidence in Britain may be brought into relation with that of the Continent.

\title{
Generation and Utilisation of Cold.
}

THE general discussion on the generation and utilisation of cold which was held at the Institution of Electrical Engineers on October I6 was organised jointly by the Faraday Society and the British Cold Storage and Ice Association.

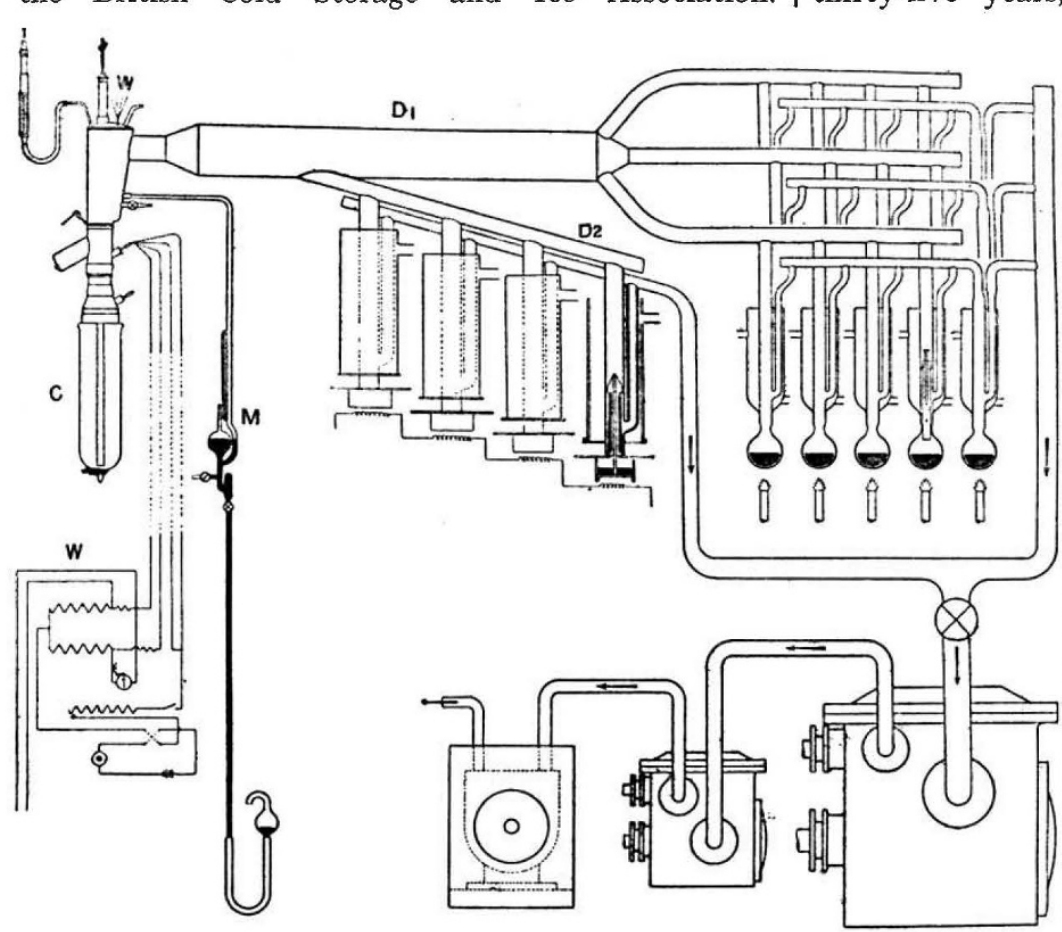

FIG. 1.-Apparatus used in attempt to solidify helium.

C, helium cryostat ; M, McLeod gauge ; W, resistance manometers ; $D_{1}$, connexion to glass Langmuir pumps; $\mathrm{D}_{2}$, connexion to iron Langmuir pumps.

present. Consequently Dr. C. A. Crommelin communicated Prof. Onnes's paper as well as his own.

The Leyden cryogenic laboratory has been engaged on low-temperature investigations for the past
thirty-five years, and such magnificent work has been done there that any communication emanating from this specialised institution is read with considerable interest.

Dr. Crommelin's paper was of the nature of a general description of the methods of experiment whereby they obtained any desired temperature below zero centigrade and maintained this temperature constant within $\mathrm{O}^{\circ} \mathrm{OI}^{\circ} \mathrm{C}$. The equipment of the cryogenic laboratory is essentially a series of plants working on regenerative Pictet cycles down to liquid nitrogen temperatures. Below this, liquid hydrogen and liquid helium are employed. In the Pictet cycles methyl chloride, nitrous oxide, ethylene, methane, oxygen, and nitrogen are used. Any one of the substances boiling under appropriate pressure will give a range of steady temperatures. By these means a range from $-24^{\circ} \mathrm{C}$. to $-270^{\circ} \mathrm{C}$. is obtained which is complete but for short gaps.

Cryostats containing the different liquids are thermally insulated by vacuum walled vessels and the losses reduced to a minimum by the immersion of the apparatus in baths of the commoner elements such as liquid oxygen.

For the range $-259^{\circ}$ to $-269^{\circ} \mathrm{C}$.,

Although the papers read at the meeting dealt with various aspects of the liquefaction of gases, there were no contributions from the refrigerating industry. Possibly the applications of cold for the preservation of food stuffs have become so standardised that our refrigerating engineers do not interest themselves in new developments. It was intended that the opening paper of the discussion should be read by Prof. H. Kamerlingh Onnes, but owing to the death of his colleague, Prof. Kuenen, he was unable to be which cannot be obtained by the use of a boiling liquid, a hydrogen vapour cryostat is employed, the vapour being heated electrically to the desired temperature and circulated around the experimental bulb.

The paper also contains some interesting data as to the capacity of the plant, and it is stated that liquid hydrogen can be produced at the rate of more than I3 litres per hour. A high degree of purity is required in the gases employed, and it appears that

No. 2766 , vOL. IIO] 
the ordinary liquid air process of producing oxygen does not give gas of sufficient purity.

Prof. Onnes's paper contains an account of his attempts at producing solid helium and, of course, the attainment of the lowest temperature. His original experiments with helium date back to fifteen years ago, when he found that liquid helium boiling under the lowest pressure he could produce (about $2.2 \mathrm{~mm}$.) did not solidify. The temperature was estimated as $I \cdot I 5^{\circ}$ absolute. In I920, Onnes determined to make a fresh attempt, using the best pumps available for reducing the pressure. Batteries of Langmuir condensation pumps were constructed, twelve of glass and six of iron, all working in parallel and delivering into two Burckhardt vacuum pumps connected in series with a Siemens oil pump. The largest Burckhardt pump was capable of dealing with 360 cubic metres of gas per hour. A diagram of the experimental arrangements is shown in Fig. $x$.

The complete battery of pumps was capable of removing one litre (N.T.P.) of gas per hour under a suction pressure of $0.005 \mathrm{~mm}$., but owing to the gas friction in the apparatus, the actual pressure produced at the surface of the helium was only 0.0I2 to 0.014 $\mathrm{mm}$. Under these conditions the lowest temperature attained was $0.82^{\circ}$ absolute. Even then helium did not solidify.

Not the least difficult part of these investigations is the measurement of temperature. The actual temperature of the liquid is obtained by calculations based upon the general equation of Van der Waal and extrapolating the temperature vapour pressure relationship for helium. The form of the extrapolated curve was compared with those obtained for various other elements as the line shows a decided curvature at normal temperatures. At the meeting Prof. Porter discussed the theoretical basis of this method of extrapolation and the possible error.

The two papers from the Leyden laboratory should prove of material assistance to the student interested in the technique of low-temperature investigations.

The industrial application of the liquefaction processes was dealt with by three speakers. Mr. K. S. Murray gave a general account of the processes employed by the British Oxygen Co. It was interesting to hear that the efficiency of the liquefaction process is not appreciably greater than that of the old barium oxide process using the reversible pressure reaction. The advantage of the liquefaction process is that it produces a purer gas. Figures for the cost of producing oxygen were given, as well as technical descriptions of the various types of rectification apparatus.

The second paper was sent by M. Claude, and in it was described a plant for the separation of hydrogen from water gas by a liquefaction process. The method can be utilised when the gas, such as that from coke ovens, is too impure to permit of the use of the catalytic reaction depending upon the con- version of carbon monoxide to carbon dioxide. The plant described is used for supplying hydrogen to a synthetic ammonia apparatus producing 5 tons of ammonia per day. An interesting feature of the apparatus is the introduction of small amounts of nitrogen into the system to serve as liquid nitrogen lubricant in the expansion engine.

In the third paper, Mr. E. A. Griffiths gave an account of the use of oxygen in breathing apparatus for airmen, and also of the plants for manufacturing liquid oxygen for this purpose. The chief difficulty in the use of cold liquefied oxygen is that of storage and transport. The mechanism of the metal vacuum vessel, which is the only practicable solution of the problem, was briefly dealt with. The manufacture of these vessels is a simple matter, and the thermal losses in properly constructed vessels is I2 per cent. of the liquid oxygen content per day for a flask of two litres capacity, while for a twenty-five-litre flask it is only $4 \frac{1}{2}$ per cent.

The vaporisers for converting the liquid oxygen into gas at a rate which can be kept under control were described. In view of the simplicity of these devices, it is surprising that greater use is not made of liquid oxygen in medical and experimental work.

The portable plants employed for producing oxygen utilise both the Claude and the Linde principles. Although the theoretical efficiency of expansion with external work is about three times that possible with the Joule-Thomson free expansion, the actual results obtained on test are not appreciably different. This appears to be due to the practical limitations of the expansion engine. A similar conclusion was arrived at independently by Mr. Murray in the case of large plants.

The expenditure of power for the production of oxygen is of the order of $2 \frac{1}{2}$ to 3 H.P. per litre/hour: the figure for the Pictet cycle, according to Crommelin, is decidedly lower, being only I.64 H.P. per litre/hour. The over-all efficiency of liquefaction processes is therefore extremely low and generally less than 3 per cent.

The remaining papers were contributed by investigators working under the direction of the Engineering Committee of the Food Investigation Board (Department of Scientific and Industrial Research).

Dr. Ezer Griffiths dealt with the determination of thermometric lag in various types of thermometers and with some new materials for thermal insulation at low temperatures.

Prof. C. F. Jenkins gave a summary of his work on the thermal properties of ethyl chloride. His research on this substance is an extension of his previous work on carbon dioxide. The data which he has now obtained should be of considerable value to the refrigerating engineer, for ethyl chloride has many advantages over ammonia and carbon dioxide for use in small refrigerating plants.

\section{E. A. Griffiths.}

\section{Propagation of the Sound of Explosions.}

I $T$ has frequently been noted that on the occasion of great explosions there are curious anomalies in the propagation of the sound. Usually there is a normal zone of audibility in the immediate neighbourhood of the explosion, beyond this a zone of silence, where the sound is not heard, and again outside the zone of silence a second zone of audibility. It is remarkable that while an observer at say $5^{\circ}$ miles away may not hear an explosion, an observer at 80 miles may hear it distinctly.

These abnormalities are closely connected with the meteorological conditions, though the detailed relationship between them is not known. One theory is that the wind lifts the sound over an area and brings it down again many miles away. Another theory ascribes the zone of silence to the effect of the distribution of wind and temperature at high altitudes. The theoretical development of the problem is extremely complex, and so it was decided to make an experimental study of the meteorological conditions along with detailed observations of the extent of the zone of silence in the hope of elucidating the relationship between them.

The International Commission for the Investigation

No. 2766 , vOL. I IO] 